\title{
Inhalt
}

\section{Gunter Martens}

Vorwort des Herausgebers (2012)

\section{Beiträge}

\section{Gunter Martens}

Wörterbuch der Editionsphilologie. Ein Aufriss der anstehenden

Probleme und Fragen (1997/2012)

Hans Zeller

Methodologie der Terminologiearbeit (1997/99)

Siegfried Scheibe

Terminologie und editorische Praxis (1997)

\section{Kurt Gärtner}

Editorische Terminologie aus mediävistischer Sicht I (1997/2012)

\section{Ulrich Müller}

Editorische Terminologie aus mediävistischer Sicht II. Überlegungen

zu den Problemen der mediävistischen Überlieferung, Edition und

ihrer Terminologie (1997/2012)

Hans Gerhard Senger

Editorische Terminologie - aus philosophiegeschichtlicher

Sicht (1997)

Winfried Woesler

Altphilologische editorische Terminologie in der Neuphilologie

$(1997 / 2012)$

Roland Reu $\beta$

Kritische Textkritik (2012)

Rüdiger Nutt-Kofoth

Variante, Lesart, Korrektur oder Änderung? Zum Problem der

Synonyme in der neugermanistischen Editionsphilologie

(2002/2006) 
Gunter Martens

Das Problem der Begriffsfelder und ihre Behandlung in einem

Fachwörterbuch. Am Beispiel des Begriffsfeldes „Textgenese“

(1997/2012)

Martin Boghardt

Buchdruck und Druckanalyse. Gegenstand, Methode, Begriffe

(1997/98)

Roger Lüdeke mit Anne Bohnenkamp und Hans Walter Gabler

Konzeption und Prototyp eines Kompendiums der

Editionswissenschaft (2006)

II Materialien

Gunter Martens

Vorbemerkung des Herausgebers zu den Wörterbuchartikeln (2012) 161

Martin Boghardt

Begriffe aus der analytischen Druckforschung (1998)

Probeartikel (1997/2012)

Liste der Begriffe und Stichwörter für das ,Wörterbuch der

Editionsphilologie“" (2006/2012)

Gunter Martens

Resümee und Ausblick (2012)

Anhang:

Klaus Hurlebusch

Nachträgliche Bemerkungen zum Artikelentwurf „Textkritik (I)“von

Winfried Woesler (1998)

Roland Reu $\beta$

Vorüberlegungen aus Anlass der Vorbereitung zweier Artikel für ein Wörterbuch editorischer Begriffe (1997)

Literaturverzeichnis zu allen Beiträgen dieses Heftes (2012) 